\title{
BSR and TSR origins for different generations of pyrite in Lower Cambrian dolomite reservoirs, Center Sichuan Basin
}

\author{
DA-WEI LIU AND CHUN-FANG CAI
}

Key Laboratory of Petroleum Research, Institute of Geology and Geophysics, Chinese Academy of Sciences, Beijing, 10029, China (liudawei@mail.iggcas.ac.cn)

Sulfur isotopic compositions have been widely used to reflect if pyrite was derived from microbial or thermochemical sulfate reduction (BSR, TSR, respectively). However, some BSR-derived pyrites from low sulfate environment show similar $\delta^{34} \mathrm{~S}$ values to TSR. Thus, it necessary to apply Nano SIMS (Secondary Ion Mass Spectrometry) technology to determine micrometer sized variation in $\delta^{34} \mathrm{~S}$. Deeply buried lower Cambrian (Longwangmiao Fm.) dolostones in central Sichuan basin contain three types of pyrite: i) framboidal pyrite aggregates (Py1); ii) intergranular solitary crystalline pyrite (Py2); iii) middle to coarse crystalline pyrite associated with hydrothermal fluid and hydrocarbon (Py3). The Py1 and Py2 have wide ranges, from -7.1 to $+10.4 \%$ and Py2 from 15.5 to $45.6 \%$, respectively. The Py1 may have precipitated from the coeval sweater with $\delta^{34} \mathrm{~S}$ from 29.5 to $34.4 \%$ during earliest diagenesis resulting in decrease in sulphate concentration in the pore water. This is followed by second generation of pyrites with $\delta^{34} \mathrm{~S}$ values increase from the centre to the edge. As the result of decreasing sulfate concentrations and Rayleigh fractionation. Different from the Py1 and Py2, Py3 shows a relatively small range, from 13.7 to $21.2 \%$, which is similar to $\mathrm{H}_{2} \mathrm{~S}$ gas $\left(\delta^{34} \mathrm{~S} 18.5 \sim 20.7 \%\right.$ ) and Neoproterozoic Dengying Formation evaporite minerals $\left(\delta^{34} \mathrm{~S} 15\right.$ to $25 \%$ ). The Py 3 is associated with $\delta^{13} \mathrm{C}$ depleted calcite and dolomite with fluid inclusions homogenization temperatures from to, supporting previous conclusions that the sulphides were generated from thermochemical reduction of up-migrated sulphate by hydrocarbon gases in the gas reservoirs with huge reserve. This case study shows that Nano SIMS can well be used to determine the origins of the pyrite, especially for the Py2, which may be wrongly identified as TSR origin. 